Картоев И.М.

\title{
ОРГАНИЗАЦИОННО-ПРАВОВЫЕ ВОПРОСЫ УСТАНОВЛЕНИЯ ПРЕДЕЛОВ ДОКАЗЫВАНИЯ ПО ДЕЛАМ ОБ ЭТНИЧЕСКИХ ПРЕСТУПЛЕНИЯХ
}

\begin{abstract}
Аннотация: в статье автором рассмотрены теоретические проблемы, касающиеся организационноправовых вопросов определения пределов доказывания по уголовным делам об этнических преступлениях, а также проблемы соотношения и взаимосвязи пределов и предмета доказывания по делам указанной категории. В статье отмечается. что производство предварительного расследования по уголовным делам об этнических преступлениях, особенно если они были совершены организованной группой лиц или характеризуются неоднократностью исполнения противоправных деяний, всегда сопряжено с определёнными сложностями в части организации и осуществления сбора и проверки процессуальных доказательств. В этой связи сразу следует отметить, что результаты оперативно-розыскной деятельности, в том числе полученные негласным путём, могут быть использованы главным образом в качестве ориентирующей информации Методологическую основу статьи составили современные достижения теории познания. В прочессе исследования применялись общефилософский, теоретический, общефилософские методы (диалектика, системный метод, анализ, синтез, аналогия, дедукция, наблюдение, моделирование), традиционно правовые методы (формально-логический), а также методы, используемые в конкретно-социологических исследованиях (статистические, экспертные оценки и др.). В статье отмечается, что с правовым институтом предмета доказывания тесно связано понятие пределов доказывания, под которыми принято понимать необходимую и достаточную степень исследованности обстоятельств, входящих в предмет доказывания, дающую возможность фактического и юридического обоснования решений, принимаемых в прочессе производства по делу. Это - характеристика результата прочесса доказывания, отражающая диалектику количественных и качественных изменений знания об обстоятельствах дела, раскрывающая познавательную деятельность в динамике её развития от вероятных к достоверным знаниям.
\end{abstract}

Ключевые слова: процесс, преступление, правонарушение, состав, ответственность, этническая, расследование, доказывание, доказательство, уголовный.

П роизводство предварительного расследования по уголовным делам об этнических преступлениях, особенно если они были совершены организованной группой лиц или характеризуются неоднократностью исполнения противоправных деяний, всегда сопряжено с определёнными сложностями в части организации и осуществления сбора и проверки процессуальных доказательств. В этой связи сразу следует отметить, что результаты оперативно-розыскной деятельности, в том числе полученные негласным пу- тём, могут быть использованы главным образом в качестве ориентирующей информации. ${ }^{1}$

\footnotetext{
См.: Фёдоров А.А., Глушков А.И. Свидетельский иммунитет как институт уголовно-процессуального права // Российский судья. 2006, № 10. С.9-12; Глушков А.И. Взаимодействие следователя и оперативных сотрудников в рамках оперативно-розыскного обеспечения уголовного судопроизводства // Вестник Московского городского педагогического университета. Серия: Юридические науки. 2008. № 1. С. 68-73; Глушков А.И., Головко Н.В. Организация взаимодействия следователя по противодействию торговли деть-
} 
Неукоснительное соблюдение процессуальных правил собирания и проверки доказательств, обязательное установление всех обстоятельств совершения этнических преступлений и входящих в предмет доказывания по уголовному делу, а также надлежащая организация всестороннего и полного расследования дел о преступлениях указанной категории - факторы, которые в значительной степени обеспечивают качественное проведение судебного разбирательства и эффективность отправления правосудия.

С правовым институтом предмета доказывания тесно связано понятие пределов доказывания, под которыми принято понимать необходимую и достаточную степень исследованности обстоятельств, входящих в предмет доказывания, дающую возможность фактического и юридического обоснования решений, принимаемых в процессе производства по делу. Это - характеристика результата процесса доказывания, отражающая диалектику количественных и качественных изменений знания об обстоятельствах дела, раскрывающая познавательную деятельность в динамике её развития от вероятных к достоверным знаниям. ${ }^{2}$

В уголовно-процессуальном законе пределы доказывания по уголовному делу, в отличие от предмета доказывания, чётко не определены и не регламентированы. По нашему мнению, это обусловлено уже только тем, что в принципе невозможно установить и использовать единый универсальный критерий достаточности совокупности доказательств для всех видов преступлений и категорий уголовных дел.

Степень достаточности имеющейся совокупности доказательств по уголовному делу и необходимости в производстве дополнительных следственных действий определяют субъекты доказывания, которые правомочны принимать итоговые процессуальные решения. При этом осуществляющие производство по уголовному делу должностные лица принимают во внимание характер и особенности общественно опасного деяния, роль и занимаемые позиции участников судопроизводства, содержание и объём доказательственной базы.

ми и использованию рабский труд // Административное и муниципальное право. 2011, № 12. С. 53-56; Глушков А.И. Реализация в уголовно-процессуальном доказывании результатов оперативно-розыскной деятельности // Вестник университета МВД России. 2012, № 2. С. 67-69 и др.

2 См.: Громов Н.А. Уголовный процесс России: Учебное пособие. М.: Юристъ, 1998. С. 52-54.
В силу изложенных обстоятельств представляется вполне обоснованным мнение А.Б. Соловьёва о том, что собирание доказательств следует проводить до тех пор, пока дело не получит судебную перспективу вне зависимости от занятой обвиняемым позиции, в том числе и при его отказе от своей вины. Иными словами, собирание доказательств должно продолжаться до тех пор, пока у следователя не будет обоснованной уверенности в том, что отказ обвиняемого от показания не приведёт к возвращению дела на дополнительное расследование прокурором либо к прекращению дела и оправданию обвиняемого в суде. ${ }^{3}$

В этой же связи достаточно спорной следует признать точку зрения, изложенную Ф.Н. Фаткуллиным и Н.В. Жогиным по существу рассматриваемых вопросов. По их мнению, если «расследуется изнасилование, то нет необходимости с фотографической точностью воспроизводить имевшую место между обвиняемым и потерпевшей борьбу, а достаточно доказать вступление в половую связь насильственным путём и существенные моменты этого насилия. Когда предварительное следствие ведётся по факту хулиганства, необязательно детализировать все нецензурные выражения и циничные действия виновного без исключения, можно ограничиться выявлением наиболее существенных, дерзких и циничных действий, грубо нарушающих общественный порядок и выражающих явное неуважение к обществу».4

На наш взгляд, в данном случае речь идёт не о пределах, а о содержании предмета доказывания. Пределы доказывания, о которых повествуют названные авторы, определены в положениях уголовного законодательства: в нормах уголовного закона представлено описание конкретных признаков действий (бездействий), образующих основания наступления уголовной ответственности. Содержание (сущность) этих признаков конкретного общественно опасного деяния, по сути, и определяет пределы действия уголовного закона, которые должны быть учтены следователем, дознавателем, прокурором и судом применительно к конкретному преступлению в процессе доказывания.

См.: Соловьёв А.Б. Доказывание по Уголовно-процессуальному кодексу Российской Федерации (досудебные стадии). М., 2003. С. 44.

4 Жогин Н.В., Фаткуллин Ф.Н. Предварительное следствие в советском уголовном процессе. М., 1965. С. 105-108. 
Аналогичной оценки заслуживает попытка некоторых учёных акцентировать внимание на одной из сторон пределов доказывания - степени достаточности исследуемых версий и полноты обоснования выводов по делу. ${ }^{5}$ Многие авторы в последующем аналогично определяли пределы доказывания.

Так, Г.М. Миньковский считал, что это - «необходимая и достаточная совокупность доказательств, которая, будучи собранной по делу, обеспечивает правильное его решение путём установления искомого комплекса обстоятельств, подлежащих доказыванию. Понятие предмета и пределов доказывания взаимосвязаны и взаимозависимы: первое выражает цель, второе - средство её достижения». ${ }^{6}$

П.С. Элькинд под пределами доказывания понимала «объём доказательств и необходимых для их получения следственных и судебных действий, обеспечивающих полное, всестороннее и объективное установление всех компонентов предмета доказывания по каждому конкретному уголовному делу». ${ }^{7}$ Н.С. Алексеев, Л.Д. Кокорев, В.Г. Даев определили пределы доказывания как «круг, объём конкретных доказательств и следственных действий, необходимых для установления искомых обстоятельств». ${ }^{8}$ П.А. Лупинская отнесла к пределам доказывания не только объём доказательств, необходимый и достаточный для установления предмета доказывания, но и доказательственные факты. ${ }^{9}$

Не трудно заметить, что значительная часть учёных относят к пределам доказывания количественные показатели процесса доказывания. В результате, как нам представляется, происходит смешение понятий «пределы» и «фактический объём» доказывания. Между тем, модель процесса доказывания должна быть единой (общей) для всех уго-

\footnotetext{
5 См.: Фаткуллин Ф.Н. Общие проблемы процессуальные доказывания: 2-е изд. Казань, 1976. С. 70.

6 См.: Теория доказательств в советском уголовном процессе, 2-е изд. М., 1973. С. 187.

7 См.: Горский Г.Ф., Кокорев Л.Д., Элькинд П.С. Проблемы доказательств в советском уголовном процессе. Воронеж, 1978. C. 98.

8 См.: Алексеев Н.С., Даев В.Г., Кокорев Л.Д. Очерк развития науки советского уголовного процесса. Воронеж, 1980. C. 152.

9 Лупинская П.А. Решения в уголовном судопроизводстве. М., 1976. С. 81; Уголовный процесс / Под ред. П.А. Лупинской. М., 1995. С. 137-138.
}

ловных дел с точки зрения не только предмета, но и пределов доказывания.

Следует отметить, что в науке уголовного процесса разрабатывалось и иное направление исследования пределов доказывания - не только с их количественной, но и с качественной стороны. Так, например, В.Г. Танасевич соотнёс пределы доказывания с необходимой глубиной исследования обстоятельств, т.е. не с количественной характеристикой процесса доказывания (совокупностью доказательств, их источников и круга следственных и судебных действий по их установлению и получению), а с его качественной стороной - уровнем достигнутого при производстве по делу знания, его достаточности для разрешения уголовного дела по существу. ${ }^{10}$

Это научное направление получило дополнительное обоснование и развитие в трудах Л.М. Карнеевой, которая перенесла исследование пределов доказывания в плоскость самого процесса познания, осуществляемого в форме доказывания, а именно - в плоскость процесса постепенного наращивания знаний о фактических обстоятельствах дела от различных степеней вероятности, в результате чего и создаётся информационное основание процессуальных решений. Они и лежат в основе возникновения, развития и завершения производства по уголовному делу. ${ }^{11}$

В свете рассматриваемых проблем следует отметить, что при организационно-правовом обеспечении расследования этнических преступлений степень достижения пределов доказывания должна определяться не количеством применённых средств доказывания, а значением каждого из них в совокупности, необходимой для признания обстоятельств, подлежащих доказыванию и имеющих значение для дела, достаточно доказанными.

Если пределы доказывания увязывать не со степенью доказанности имеющих значение для дела обстоятельств, а рассматривать их как объём деятельности органов расследования по собиранию и проверке доказательств, то это не только будет не точным, но и некорректным по своей

\footnotetext{
10 Танасевич В.Г. Пределы и предмет доказывания по уголовному делу // Практика применения нового уголовно-процессуального законодательства. М., 1962. С.37.

11 См.: Карнеева Л.М. Привлечение к уголовной ответственности. Законность и обоснованность. М., 1971; Доказательства и доказывание при производстве расследования. Горький, 1977; Доказательства в советском уголовном процессе. Волгоград, 1988.
} 
сути. Предмет доказывания тоже определяет объём деятельности, и между объёмом деятельности и степенью доказанности нет прямой зависимости: объём деятельности может быть большим, а результат ничтожным, в связи с чем истина по делу окажется недостигнутой.

Смешение этих понятий на практике приводит к тому, что в итоговых документах (обвинительном заключении, постановлении о прекращении дела или уголовного преследования) работники органов расследования вместо анализа доказательств, подтверждающих выводы, ограничиваются простым перечислением источников доказательств. А для создания видимости подтверждения признания обвиняемым своей вины совокупностью доказательств, как того требует закон (ч.2 с.77 УПК РФ), в ряде случаев приводят перечень следственных действий, ничем его не подтверждающих, на что, кстати, справедливо обращали внимание многие авторы. ${ }^{12}$

При организационно-правовом обеспечении расследования этнических преступлений также необходимо содержание понятия пределов доказывания сопоставлять с объёмом процессуального доказывания. Это позволит, во-первых, определить значение и место в процедуре установления истины по делу его количественных и качественных сторон в неразрывной связи с целью - предметом доказывания; во-вторых, получить чёткое представление о требованиях закона по поводу пределов доказывания.

По нашему мнению, одним из обязательных условий для правильного разрешения вопроса о пределах доказывания по делам об этнических преступлениях является системное рассмотрение процесса доказывания как познавательно-удостоверительной деятельности следователя и дознавателя, регламентируемой уголовно-процессуальным законом.

Целью процессуального доказывания по уголовным делам о преступлениях указанной категории является установление обстоятельств, образующих предмет доказывания. Пределы доказывания производны от цели и представляют

12 См., напр.: Шейфер С.А. Следственные ошибки: понятие, классификация и взаимосвязи // Уголовно-правовые и процессуальные проблемы: Межвуз. сб. статей. Куйбышев, 1987. № 12. С. 46-48; Шейфер С.А., Лазарева В.А., Исмакаев Л.П. Следственные ошибки и их причины // Проблемы дальнейшего укрепления социалистической законности при расследовании преступлений органами внутренних дел. Межвуз. сб. науч. трудов. Киев, 1988. С. 118-126. собой определяемый законом результат познания истины. Наряду с понятием предмета доказывания, научное понятие пределов доказывания является важнейшей характеристикой познавательной деятельности следователя и дознавателя, придаёт ей целеустремлённость и освобождает указанных лиц от ненужной работы. Оно позволяет ясно представлять себе различия в характере выводов об искомых обстоятельствах, которые делаются на разных этапах процесса. Главное же: исследование пределов доказывания требует углублённого анализа логики доказывания, овладения приёмами построения различных по характеру комплексов доказательств, обеспечивающих надёжность выводов следователя и дознавателя. ${ }^{13}$

С учётом изложенного можно сделать вывод, что сущность понятия пределов доказывания отражает диалектику количественных и качественных изменений знания об обстоятельствах уголовного дела, раскрывает познавательную деятельность в динамике её развития от вероятных к достоверным выводам. Определённая законом процедура доказывания реализуется следователем и дознавателем в его фактическом объёме, представляющем собой «инструментальную часть» данной процедуры.

Фактический объём процессуального доказывания включает в себя совокупность доказательств, их источников, комплекс следственных действий, призванных обеспечить всестороннее, полное и объективное установление и исследование всех элементов предмета доказывания в необходимых для конкретного уголовного дела пределах. Он зависит от количества исходной информации при возбуждении уголовного дела, количества выдвинутых и подлежащих проверке версий и подлежащих исследованию эпизодов, следственной ситуации в тот или иной период производства по делу, от индивидуальных особенностей следователей и судей как специалистов.

По уголовным делам об этнических преступлениях фактический объём процессуального доказывания определяется, корректируется и реализуется следователем и дознавателем с учётом требований закона по поводу предмета и пределов доказывания путём планирования и непосредственного осуществления ими предварительного расследования. В этом аспекте он

13 См.: Шейфер С.А. Доказательства и доказывание по уголовным делам: Проблемы теории и правового регулирования. Тольятти, 1988. С. 28. 
представляет собой реализацию нормативных предписаний. В то же время конкретное заранее установленное количество доказательств и способов их получения (собирания) не могут быть изначально определены.

Пределы и предмет доказывания, как качественные характеристики данной процессуальной деятельности, предполагают фактический объём доказывания, планируемый и реализуемый при производстве по уголовному делу следователем и дознавателем с учётом особенностей конкретного преступления, хода расследования, течение и результаты которого ни один закон не в состоянии заранее предусмотреть и описать.

На наш взгляд, изложенное соотношение рассматриваемых понятий позволяет в процессе доказывания держать под контролем как степень исследованности конечного результата, так и достижение промежуточных целей на пути к нему, что в свою очередь имеет важное практическое значение для организационно-правового обеспечения законности и обоснованности принимаемых следователем и дознавателем решений по уголовному делу о преступлениях указанной категории.

\section{Библиография:}

1. Соловьёв А.Б. Доказывание по Уголовно-процессуальному кодексу Российской Федерации (досудебные стадии). М., 2003.

2. Шейфер С.А. Доказательства и доказывание по уголовным делам: Проблемы теории и правового регулирования. Тольятти: Волжский университет им. В. Н. Татищева, 1998.

3. Орлов Ю.К. Основы теории доказательств в уголовном процессе. Науч.-практич. пособие. М., 2001.

4. Строгович М.С. Избранные труды. Т.3. Теория судебных доказательств. М., 1991.

5. Чурилов С.Н. Предмет расследования преступления: проблемы, пути решения. М., 2002.

6. Кузнецов Н.П. Доказательства и доказывание // Уголовный процесс России / Под ред. З.Ф. Ковриги, Н.П. Кузнецова. Воронеж, 2003.

7. Уголовно-процессуальное право Российской Федерации: Учебник / Под ред. П.А. Лупинской. М.: Норма, 2009.

8. Григорьев В.Н., Победкин А.В., Яшин В.Н. Уголовный процесс: Учебник. М.: Эксмо, 2009.

9. Афанасьяди В.Г. Реализация результатов оперативно-розыскной деятельности в доказывании по уголовным делам о незаконном усыновлении // Административное и муниципальное право. - 2013. 8. - C. 811-814. DOI: 10.7256/1999-2807.2013.8.9283.

10. Терехов А.Ю. К вопросу об основаниях выбора способа собирания доказательств в ходе досудебного производства по уголовному делу // Полицейская деятельность. - 2011. — 4. - C. 45-50.

11. Костенников М.В., Куракин А.В. К вопросу об основании административной ответственности в российском праве // NB: Административное право и практика администрирования. - 2013. - 10. C. 75-88. DOI: 10.7256/2306-9945.2013.10.10153. URL: http://www.e-notabene.ru/al/article_10153.html

12. Костенников М.В., Куракин А.В., Трегубова Е.В. Конституционное право на проведение мирных собраний, митингов, демонстраций, шествий и пикетирования и административная ответственность как средство его обеспечения // NB: Административное право и практика администрирования. - 2013. — 8. C. 82-105. DOI: 10.7256/2306-9945.2013.8.9955. URL: http://www.e-notabene.ru/al/article_9955.html

\section{References:}

1. Solov'ev A.B. Dokazyvanie po Ugolovno-protsessual'nomu kodeksu Rossiiskoi Federatsii (dosudebnye stadii). M., 2003.

2. Sheifer S.A. Dokazatel'stva i dokazyvanie po ugolovnym delam: Problemy teorii i pravovogo regulirovaniya. Tol'yatti: Volzhskii universitet im. V. N. Tatishcheva, 1998.

3. Orlov Yu.K. Osnovy teorii dokazatel'stv v ugolovnom protsesse. Nauch.-praktich. posobie. M., 2001.

4. Strogovich M.S. Izbrannye trudy. T.3. Teoriya sudebnykh dokazatel'stv. M., 1991.

5. Churilov S.N. Predmet rassledovaniya prestupleniya: problemy, puti resheniya. M., 2002.

6. Kuznetsov N.P. Dokazatel'stva i dokazyvanie // Ugolovnyi protsess Rossii / Pod red. Z.F. Kovrigi, N.P. Kuznetsova. Voronezh, 2003. 
7. Ugolovno-protsessual'noe pravo Rossiiskoi Federatsii: Uchebnik / Pod red. P.A. Lupinskoi. M.: Norma, 2009.

8. Grigor'ev V.N., Pobedkin A.V., Yashin V.N. Ugolovnyi protsess: Uchebnik. M.: Eksmo, 2009.

9. Afanas'yadi V.G. Realizatsiya rezul'tatov operativno-rozysknoi deyatel'nosti $\mathrm{v}$ dokazyvanii po ugolovnym delam o nezakonnom usynovlenii // Administrativnoe i munitsipal'noe pravo. - 2013. - 8. - C. 811-814. DOI: 10.7256/1999-2807.2013.8.9283.

10. Terekhov A.Yu. K voprosu ob osnovaniyakh vybora sposoba sobiraniya dokazatel'stv v khode dosudebnogo proizvodstva po ugolovnomu delu // Politseiskaya deyatel'nost'. - 2011. - 4. - C. 45-50.

11. Kostennikov M.V., Kurakin A.V. K voprosu ob osnovanii administrativnoi otvetstvennosti v rossiiskom prave // NB: Administrativnoe pravo i praktika administrirovaniya. - 2013. - 10. - C. 75-88. DOI: 10.7256/23069945.2013.10.10153. URL: http://www.e-notabene.ru/al/article_10153.html

12. Kostennikov M.V., Kurakin A.V., Tregubova E.V. Konstitutsionnoe pravo na provedenie mirnykh sobranii, mitingov, demonstratsii, shestvii i piketirovaniya i administrativnaya otvetstvennost' kak sredstvo ego obespecheniya // NB: Administrativnoe pravo i praktika administrirovaniya. - 2013. - 8. - C. 82-105. DOI: 10.7256/2306-9945.2013.8.9955. URL: http://www.e-notabene.ru/al/article_9955.html 